\title{
MEDIADORES DE LEITURA NO HOSPITAL PEDIÁTRICO: RELATOS DE SUA PRÁTICA
}

1 Universidade de Brasília

\author{
E.P.Flores $^{1 *}$; B.L. Yamada ${ }^{1}$; V.G. Loyola $^{1}$; A.R. Dias ${ }^{2}$
}

2 Hospital Materno Infantil de Brasília

\author{
*eileen@unb.br
}

\section{RESUMO}

Este estudo investigou as concepções de nove voluntários de uma organização não-governamental acerca de sua prática de mediação de leitura no contexto hospitalar. Por meio de mapas conceituais, foram analisadas as entrevistas semiestruturadas feitas com cada mediador, resultando em 376 proposições, cujo agrupamento semântico resultou em 13 categorias. Os resultados mostram que os mediadores relacionam sua atuação ao altruísmo e conceituam, sobretudo, como uma maneira de trazer alívio e alegria em um ambiente visto como extremamente aversivo. São feitas poucas menções aos benefícios que seriam específicos da mediação de leitura. $\mathrm{O}$ estudo permite conhecer melhor alguns desafios específicos da mediação de leitura em contexto hospitalar e sugerir estratégias para a formação inicial e continuada de mediadores no futuro.

\section{STORYTELLERS WORKING IN A CHILDREN'S HOSPITAL: REPORTS ON THEIR PRACTICE}

\begin{abstract}
This study investigated the concepts of nine volunteers from a non - governmental organization who read stories to hospitalized children. We conducted three to five semistructured interviews with each storyteller which were analyzed using concept maps, resulting in 376 propositions. A semantic grouping of the propositions resulted in 13 categories. Results suggest that storytellers associate their activities to altruism and conceive it
\end{abstract}

chiefly as a way of bringing relief and joy to children in the hospital environment, seen as extremely aversive. Few references are made to the specific features and benefits of shared reading. The study reveals characteristics and challenges which are specific to the practice of shared reading in the hospital setting and suggests directions for volunteer training in this context.

KEYWORDS: Storytellers; Volunteers; Hospital; Children; Brazil 


\section{INTRODUÇÃO}

A hospitalização na infância, especialmente quando prolongada ou repetida, traz mudanças na rotina da criança, como limitação de mobilidade e de acesso a atividades apreciadas, obrigação de seguir rotinas rígidas, restrição do convívio social, procedimentos médicos invasivos e necessidade de confiar em pessoas desconhecidas, fatores que podem se associar a sentimentos de ansiedade, depressão, perda do sentimento de autodeterminação, dentre outros (e.g., Coyne, 2006; Kashani, Barbero \& Bolander, 1982). Os prejuízos podem incluir a dificuldade em retomar as atividades na escola ao ter alta (Ortiz \& Freitas, 2002). Apesar da obrigatoriedade do Estado de garantir continuidade ao processo educacional da criança hospitalizada, (Constituição Federal, Capítulo III, Seção I - artigo 205; Leis de Diretrizes e Bases da Educação; Resolução 41/95 do Conselho Nacional da Criança e do Adolescente), a classe hospitalar ainda é uma realidade precária no Brasil: em 2010 existiam apenas 275 turmas hospitalares em todo o país (dados fornecidos pelo MEC/INEP/DEED em 2011 aos autores, por e-mail). A proporção é ínfima, quando considerado o número de unidades hospitalares com serviço de internação (6.743 em 2009, segundo dados do Instituto Brasileiro de Geografia e Estatística, IBGE).

Uma das maneiras de amenizar os prejuízos citados e contribuir para a humanização no contexto pediátrico é oferecer às crianças e aos jovens hospitalizados encontros de leitura compartilhada (leitura em voz alta de textos infanto-juvenis por um mediador). Já existem estudos no Brasil que investigaram aspectos desse tipo de serviço (ver Revisão da literatura a seguir). .

Em um estudo anterior (Flores, Fiuza, Motta \& Dias, 2013), foram realizadas observações do momento de interação entre os mediadores dessa mesma organização e as crianças hospitalizadas com o objetivo de descrever as intervenções realizadas durante a leitura compartilhada pelos voluntários. Os resultados revelaram quatro tipos de intervenções por parte dos mediadores: (1) Leitura e descrição dos textos e/ou das ilustrações; (2) Pedidos e encorajamentos para a criança falar/participar/responder (3) Elogios ou correções de falas/gestos das crianças (4) Intervenções com função de dirigir o olhar da criança para o livro ou de ensinar o manuseio adequado do livro (como segurar, evitar rasgar, virar as páginas, etc.). Os resultados mostraram, portanto, que os mediadores realizavam a mediação de leitura de forma bastante interativa. No entanto, conversas informais nas reuniões com os voluntários sugeriram que as estratégias eram usadas de forma intuitiva, mas eram acompanhadas de ansiedade e dúvidas variadas sobre como realizar melhor o trabalho, especialmente quanto à escolha dos livros, quanto à leitura com crianças de idades diferentes e quanto ao desconforto com o ambiente hospitalar.

A partir dessas interações informais, surgiu o objetivo principal deste trabalho: investigou as 
concepções de voluntários de uma organização não-governamental acerca de sua prática de mediação de leitura no contexto hospitalar, incluindo os principais desafios enfrentados. Um objetivo secundário foi verificar se os contadores concebiam seu trabalho, além do aspecto de humanização da saúde, também como uma contribuição para o fomento à leitura e para a formação de novos leitores. Em conjunto com os dados observacionais obtidos anteriormente (Flores et al., 2013), o presente estudo visa contribuir para o conhecimento das características e dos desafios específicos da mediação de leitura em contexto hospitalar, o que poderá embasar o planejamento de estratégias de formação inicial e continuada dos voluntários.

\section{Revisão Bibliográfica}

Alguns estudos vêm sugerindo que a leitura compartilhada pode ser um fator importante de humanização no contexto hospitalar. Moreno et al. (2003) investigaram como mediadores de leitura em um hospital infantil para investigar como percebiam as reações das crianças, dos acompanhantes e dos profissionais de saúde durante as leituras. Aplicaram um questionário a 283 mediadores voluntários. Constataram que os mediadores percebiam uma reação muito positiva (atenta, entusiasmada, alegre) por parte das crianças e dos acompanhantes, mas menos presença da equipe médica. Entrevistas abertas com crianças, acompanhantes, profissionais de saúde e mediadores mostraram como principais temas (1) alívio da dor, esquecimento da doença, melhor aceitabilidade dos procedimentos médicos e até melhoria no estado de saúde; (2) Sentimentos de alegria e autoestima (3) "Viagem ao mundo da fantasia" e (4) construção do processo ou hábito de leitura. No entanto, os resultados das entrevistas abertas não foram separados em termos de quem as expressou (crianças, profissionais, mediadores ou acompanhantes). Não se sabe, portanto, quais desses temas foram abordados especificamente pelos mediadores.

Ceribelli e colaboradores (2009) investigaram como a mediação de leitura pode ser usada enquanto ferramenta de comunicação com crianças hospitalizadas. Participaram crianças de três a 12 anos de idade e nove mediadores de leitura voluntários da organização "Viva e Deixe Viver" em Ribeirão Preto. Nas entrevistas semiestruturadas, todos os mediadores declararam ter algum ganho pessoal com a sua atuação, sendo este um ganho em termos de aprendizado e crescimento individual. A vontade de "fazer algo para os outros" foi citada como principal motivo para ingresso no projeto voluntário. A partir da fala dos contadores, foram listadas alguns prováveis benefícios da leitura compartilhada: a catarse de conflitos internos; aprendizagem; redução de estresse proveniente da hospitalização; bem-estar; resolução de problemas; encorajamento para buscar respostas e o despertar da curiosidade. 
Caldin (2002) investigou as concepções de estudantes que participavam de um trabalho de extensão universitária e contavam histórias para as crianças da ala pediátrica de um hospital universitário, com o objetivo de diminuir seus níveis de estresse, usando os princípios da biblioterapia. Antes dos encontros com as crianças, os mediadores se preparavam por meio da escolha das obras e do ensaio da leitura em voz alta e eram encorajados a justificar a escolha de cada obra. Os mediadores produziram relatórios de sua experiência em que destacaram (1) o caráter gratificante da atividade de mediação (2) os critérios usados para a escolha do livro, que incluíram a leveza e alegria dos relatos, não cansar as crianças, permitir a participação de várias faixas etárias, estimular a imaginação e serem adequados aos objetivos da biblioterapia; (3) a importância da orientação recebida nos encontros semanais; (4) a alegria, o alívio e a descontração das crianças durante as leituras; (5) a interrupção das leituras pela equipe médica, considerada a principal dificuldade (6) a dificuldade em realizar, de fato, a mediação de leitura, substituindo-a muitas vezes pelo conto oral

Grande parte das intervenções de humanização hospitalar, como as que foram citadas, depende do serviço voluntário. O estudo do voluntariado tem suas raízes na Psicologia social, com pesquisas a respeito dos comportamentos de ajuda (Darley \& Batson, 1973; Eisenberg \& Miller, 1987). Somente a partir de 1980, com o trabalho de Benson et al. (1980), o voluntariado passou a ser compreendido com um tipo diferenciado de comportamento de ajuda que requer planejamento a longo prazo e comprometimento a um serviço por um período de tempo considerável. Desde então, uma das perguntas centrais no estudo do voluntariado tem sido: O que faz uma pessoa se voluntariar? (Anderson \& Moore, 1978). Quando os voluntários descrevem a importância da sua atuação, em muitos casos, deixam também transparecer os fatores que contribuíram para que eles se tornassem voluntários e isso tem grande relação com a forma como percebem seu trabalho e com os resultados atingidos. Funcke, Pereira e Vilas Boas (2007) afirmam que, em se tratando de um trabalho não-remunerado, os fatores motivacionais e de produtividade têm forte ligação com motivações individuais.

\section{MATERIAIS E MÉTODOS}

\section{Contexto do presente estudo.}

A Associação Viva e Deixe Viver (VIVA), organização em que ocorreu a presente pesquisa, é uma OSCIP (Organização da Sociedade Civil de Interesse Público) que forma e acompanha voluntários que leem histórias para crianças e adolescentes hospitalizados. Há uma forte ênfase na difusão do livro e do prazer da leitura e, no treinamento, os voluntários são instruídos a interagir com as crianças usando livros de literatura infantil e infanto-juvenil. No hospital pediátrico em que 
ocorreu a pesquisa, havia à época um acervo de aproximadamente mil volumes à disposição dos voluntários no hospital e estes também eram encorajados, no treinamento inicial e continuado, a ampliar seu conhecimento sobre a literatura infanto-juvenil. Para destacar essas características do trabalho dos voluntários, que envolve necessariamente a leitura compartilhada, e diferenciá-lo, por exemplo, de trabalhos que dão mais ênfase à narrativa oral, será utilizado o termo "mediador(a)(es) de leitura", ou simplesmente "mediadores(as)", para referir-se a aos voluntários, embora a Associação utilize o termo mais genérico e acessível "contador de histórias".

\section{Participantes:}

Participaram nove mediadores de leitura, sete do sexo feminino. que atuavam em um hospital pediátrico localizado na cidade de Brasília, Distrito Federal, vinculados à OSCIP Viva e Deixe Viver (VIVA). A faixa etária de oito dos mediadores estava entre 25 e 29 anos e um deles tinha mais de 50 anos. Um dos mediadores possuía o Ensino Médio completo e os demais possuíam o Ensino Superior completo. Todos tinham ao redor de um ano de experiência no VIVA, com exceção de um que possuía mais de cinco anos de experiência.

\section{Local e material:}

As entrevistas foram realizadas pela primeira autora e, sob sua orientação, por estudantes do Estágio Profissional Psicólogo em uma instituição de ensino superior de Brasília, em uma sala do hospital destinada ao uso dos voluntários, nos dias em que estes atuavam no hospital, logo após eles terem terminado o trabalho previsto para aquele dia. As entrevistas foram registradas com gravador digital (mp3 ou mp4) e transcritas pelos estudantes, sob orientação da primeira e última autoras. Os mapas conceituais, descritos adiante, foram elaborados usando-se o software CmapTools, versão 5.04.02.

\section{Procedimento:}

Cada mediador era convidado individualmente a participar da pesquisa e após apresentação dos objetivos da pesquisa e do procedimento, era solicitada a assinatura Termo de Esclarecimento Livre e Esclarecido (TCLE). Os eixos orientadores para as entrevistas foram: conhecer como os mediadores percebiam seu trabalho de mediação e se percebiam nesse trabalho, suas dúvidas e reflexões, suas concepções acerca da natureza e dos benefícios do trabalho realizado, desafios enfrentados e estratégias utilizadas. As entrevistas ocorriam individualmente em três a quatro encontros de, no máximo, 50 minutos cada. A primeira entrevista se iniciava com o pedido: "Faleme de sua experiência como contador(a)". As perguntas seguintes eram formuladas a partir dessa primeira fala e dos eixos orientadores citados. As entrevistas seguintes buscaram aprofundar os temas abordados no primeiro encontro e tinham como contexto, além da primeira entrevista, também observações da atuação dos mediadores realizadas entre as entrevistas (cf. Flores et al., 
2013).

\section{Análise das entrevistas:}

Após a transcrição das entrevistas, estas foram, primeiramente, analisadas com a técnica dos mapas conceituais (Ausübel,1963; Dalley, 2004). Os mapas conceituais representam as ideias presentes nas entrevistas e as relações entre elas. Os conceitos são representados por nódulos da rede e as ligações, por setas que relacionam um conceito a outro. As setas possuem direção (podem ser bidirecionais em alguns casos). Por exemplo, se o entrevistado afirma que o livro é algo que distrai a criança, os conceitos de "criança" e "livro", no mapa, estarão ligados pelo conceito de distração, na direção de "livro" para "criança. Cada conceito pode estar ligado a mais de um conceito e em várias direções, formando-se assim uma rede conceitual.

Após elaborar os nove mapas conceituais, um para cada entrevistado, elaborou-se um mapa geral que foi nomeado de "metamapa", usando-se a ferramenta autolayout do CMapTools, que mesclou todos os conceitos que se repetiam e/ou estavam associados nos mapas individuais, permitindo ver todos os conceitos citados nas entrevistas e suas ligações. Em seguida, todas as proposições presentes no metamapa foram listadas, totalizando 394 proposições, e estas foram então agrupadas em categorias mais amplas. Como exemplo, as proposições "a história distrai a(s) criança (s)", "Criança (s) mudam o astral por causa da contação" e "A história tira a criança do ambiente ruim do hospital" foram reunidas na categoria que foi resumida como "Efeitos positivos da leitura/contação para crianças". As treze categorias resultantes da análise são descritas e exemplificadas a seguir.

\section{RESULTADOS E DISCUSSÃO}

Das 394 proposições presentes no metamapa, dez foram classificadas como "outras" e oito foram excluídas por apresentavam erros cometidos no processo de transposição ao mapa conceituais. O agrupamento semântico das demais proposições resultou em 13 categorias, compostas a partir de 376 proposições. A seguir, são descritas e discutidas as categorias e, quando pertinente, citam-se trechos ilustrativos das entrevistas, usando-se pseudônimos para se referir aos entrevistados. Algumas categorias são discutidas juntas por apresentarem relações estreitas entre si.

\section{História pessoal (31 proposições):}

As proposições desta categoria sugerem que a vida pessoal tem uma série de relações com a escolha do mediador por atuar no serviço voluntário. Uma das temáticas que surgem com frequência é a forte vocação para o voluntariado, sendo essa vocação anterior ao interesse específico pela mediação de leitura. Helena, por exemplo, iniciou o serviço voluntário trabalhando com crianças 
HIV-positivas: "Então eu fiquei sabendo do curso pela internet e depois eu vi que era um curso mais estruturado e fiz pra atender a demanda do outro trabalho voluntário [com crianças HIV positivas] que a gente faz." (Entrevista 1). De maneira semelhante, Geraldo explica como a vontade de fazer um trabalho voluntário antecedeu o interesse específico pelo trabalho com mediação de leitura: "(...) há um pouco mais de um ano, eu resolvi fazer um trabalho voluntário, então procurando, tive a ideia de trabalhar no hospital, para ler livros para as pessoas. Nessa época por acaso, descobri um curso de contador de histórias" (Geraldo, Entrevista 1)

\section{Encanto/Admiração pelo projeto (12 proposições):}

Boa parte dos entrevistados declarou espontaneamente admiração pela organização em que estão engajados: "Eu fiquei encantada pelo Viva" e "Eu acho o trabalho do Viva bacana". Também se destacaram proposições que fazem referência clara à confiança nos valores da organização: "O Viva é um projeto sério". A relação entre a confiança nos valores da organização e a motivação para o trabalho aparece em outros estudos (e.g. Araújo \& Oliveira, 2008; Pedroso, França, Oliveira \& Osawa, 2012) e foi explicitada por Helena ao responder uma pergunta referente ao motivo que a fez começar a contar histórias no projeto:

"(...) então eu fiquei sabendo do curso pela internet e depois eu vi que era um curso mais estruturado (...) e quando eu cheguei na primeira reunião eu fiquei tão encantada pelo trabalho, pelo sentido, pelo objetivo e pela organização e principalmente porque a associação viva é muito organizada. Eu fiquei tão encantada que resolvi experimentar...". (Entrevista 1)

\section{Motivação para o trabalho (37 proposições):}

Três temas foram predominantes ao tratar da motivação para o ingresso e a continuidade na Associação: (1) gratificação pessoal e prazer na atuação, (2) "fazer o bem" e (3) trabalhar com crianças. Os dois primeiros temas apareceram no mapa conceitual em proposições como: “A contação foi motivada por querer fazer o bem" e aparecem relacionados, no sentido de que a sensação de estar "fazendo o bem" traz sentimentos de gratificação. O benefício recebido pelos mediadores do Viva é percebido como sendo até maior do que o benefício gerado pelo seu trabalho:

"Acho que minha maior motivação foi a caridade mesmo... de querer fazer o bem, sabe?...de carinho mesmo, sabe?...eu acho que...eu não tenho dinheiro (risos)...eu acho que um pouquinho do que você fizer ajuda...então... assim...foi pra me doar um pouco me sentir bem...as vezes pode até parecer um egoísmo meu...né? assim...meu Deus do céu, eu fui pra me sentir bem?... mais não...eu fui pra poder estar em contato com a caridade, sabe?..." (Carla, Entrevista 1).

Essa sensação forte de gratificação e, por vezes, até mesmo de um pouco de culpa por sentir 
que o benefício para si próprio chega a superar o benefício produzido no trabalho voluntário foi também citada por voluntários da área da saúde, entrevistados por Selli, Garrafa e Junges (2008a) e pelos participantes dos estudos de Caldin (2002) e de Ceribelli (2009) Selli \& Garrafa (2005b), afirmam que o trabalho voluntário tende a se pautar pelo conceito de solidariedade e de realização de atividades socialmente relevantes e isso é claro na fala de Helena:

"Eu senti que seria bom, não só para as crianças, mas pra mim! Eu acho...que como cidadã mesmo! Eu acho que tô fazendo um trabalho importante. Algumas pessoas encaram isso até como um hobby, um alívio de consciência. Eu não sei...eu acho que...eu quero acreditar que com esse trabalho eu tô contribuindo para o futuro do país! Eu acredito nisso e não me decepcionei nem um pouco." (Entrevista 1).

\section{Aversividade do contexto hospitalar (60 proposições) e Direito de escolha da criança (6 proposições):}

A dificuldade em estar no hospital é central no relato dos entrevistados. O contexto hospitalar é descrito como um ambiente extremamente aversivo em 31 proposições ("Hospital não tem lugar para alegria."; "Hospital é muito hostil.”). As demais proposições relatam um aprendizado de formas de lidar com esses aspectos aversivos e/ou de uma relação de tranquilidade adquirida (“Sinto que é possível estar no hospital” e "Estou adaptada à rotina hospitalar"). Os próprios relatos de superação, de ter tido que aprender a "lidar" com o hospital, ressaltam a força da aversividade percebida do ambiente, pelo menos inicialmente.

A aversividade do hospital é ressaltada também a partir do lugar ocupado pela criança, ou seja, as falas destacam que o hospital é hostil, não (apenas) enquanto lugar de trabalho do mediador, mas (sobretudo) para as crianças que lá estão internadas. Os mediadores relatam que o sofrimento não se dá apenas pelo contato direto com o ambiente físico do hospital, mas sobretudo pelo contato com o sofrimento das crianças que ali estão. Uma das contadoras, ao relatar sua experiência, contou que enfrentou seu medo do hospital quando viu que isso era necessário para que o trabalho pudesse beneficar as crianças: "[a gente aprende] como lidar com esse ambiente de hospital, porque é uma situação muito difícil pra criança né" (Ana, entrevista 1). Essa percepção é complementada, em muitos casos, pela expressão do desejo de enxergar a criança além da doença e/ou de não reduzir a criança ao seu quadro: "mesmo doente a criança, ela... enfim, a criança é criança de qualquer jeito, doente ou não-doente..." (Eliana, entrevista 1).

Nesse contexto, os mediadores valorizam a hora de ler histórias como um raro momento de escolha para as crianças, o que foi revelado no mapa conceitual em proposições como "Criança tem direito a não querer a contação" e "Crianças gostam de escolher o livro". Dar à criança esse direito 
faz parte das diretrizes do VIVA e é um aspecto enfatizado no treinamento inicial dos voluntários. Num ambiente marcado pelo caráter compulsório de quase todos os aspectos do cotidiano, essa pode ser uma das poucas oportunidades para a criança ter o direito de decidir: ...mas é uma coisa que acontece, às vezes você já chega "Quer ouvir uma historinha? Sou contador de história" e a criança "Nãooo." Aí tudo bem... a criança tem todo direito de não querer." (Beto, Entrevista 1)

\section{Feedback da criança (33 proposições) e Papel e comportamento do acompanhante (16 proposições):}

Essas duas categorias englobam as proposições do mapa conceitual que fazem referência às respostas, reações e interações da criança e de seu acompanhante frente a atuação do mediador. As crianças foram descritas como muito participativas, mesmo considerando a situação difícil que estavam vivenciando (e.g., "Crianças, mesmo doentes, participam muito") (14 proposições). Um outro subtipo de proposição dentro dessa categoria realçava o feedback positivo para a motivação do contador (e.g., "Risadas das crianças são gratificantes para o contador") (15 proposições). Tomando-se esses dois tipos de proposições, nota-se que o feedback positivo era frequente e, ao mesmo tempo, extremamente encorajador para os mediadores:

"Teve uma vez, duas semanas atrás que eu contei na emergência e ali, na recepção, juntou umas cinco ou seis crianças pra ouvir, e tinha uma menininha que chegou depois e que ficava o tempo todo com um sorrisão assim aberto e tal, e quando uma outra começava a conversar ela virava e "chhhh..." pedia silencio e ai no final quando eu falei "então tá bom, tenho que ir agora, foi muito bom contar história pra vocês", aí eu saí e ouvi a menina comentando "Eu adorei!!", foi ótimo...foi ótimo, muito gostoso" (Alberto, Entrevista 1).

Mais rara (4 proposições) foi a menção do feedback como uma fonte de informação para mudanças ou adaptações no trabalho do contador, independentemente de ser positivo ou negativo, e.g., "A criança sinaliza com gestos ou expressões se está gostando ou não". Essa percepção é potencialmente importante pois pode servir de base para que o mediador ajuste suas estratégias de acordo com os efeitos produzidos sobre seu ouvinte, aperfeiçoando assim sua prática:

"A interação na verdade é um feedback que o ouvinte me dá, me dizendo se esta gostando ou se não está, o que eu devo mudar. Entendo que o meu trabalho esta sendo bem feito, que eu estou conseguindo chamar a atenção da criança" (Geraldo, Entrevista 2).

O feedback dos acompanhantes das crianças também foi destacado, porém de modo um pouco diferente: no caso das crianças, eram observados os aspectos corporais, como o sorriso, a postura, o olhar atento e o riso; enquanto o feedback dos pais geralmente era observado por meio de atitudes mais explícitas, como pedir uma história ou participar na interação: "É interessante, porque alguns 
pais, eles pedem pra gente a história, por exemplo, não sei se você lembra a mãe da semi-intensiva, sempre que me vê me pede história (...) Eles chamam a gente, às vezes, é bebezinho de poucos meses, tá dormindo e eles chamam. Então, eu vejo o interesse dos pais é grande, assim (...) Eu acho que nunca vi um pai que não tivesse um interesse na história" (Daniela, Entrevista 5).

Também há a percepção de que o(a) acompanhante pode viver a fantasia e o prazer da leitura e que isso pode ajudar a criar vínculos com a criança:

"Eu acho fundamental inserir a acompanhante na história porque primeiro ela vai poder contar essa história mais vezes pra criança, segundo ela vai poder se divertir porque ela também vai entrar nesse mundo de fantasia, de imaginação, de ter mesmo essa oportunidade de não ter quando ela era criança. Eu vejo muitas mães que nunca viram um livro infantil, elas se divertem às vezes até mais que o filho com o livro. Em terceiro, eu acho que quando você coloca a família, geralmente a mãe que acompanha a criança, você coloca a família dentro da história, você acaba criando um laço entre eles.” (Helena, Entrevista 5).

O feedback é considerado essencial para o bem-estar no trabalho (Cavassani, Cavassani \& Biazin, 2006). Cavalcante, de Oliveira, Medeiros, de Souza e Neto (2001), por exemplo, realizaram uma análise fatorial a partir de entrevistas com voluntários de organizações não-governamentais que revelou que um dos principais fatores associados à satisfação na atividade voluntária é o feedback dos agentes. As falas dos mediadores entrevistados neste estudo, a partir de uma abordagem qualitativa, confirmam importância do feedback positivo para o bem-estar no serviço voluntário e o senso de gratificação já descrito. No entanto, quando não ocorre, pode produzir sentimentos de desesperança e angústia:

"Hoje me bateu um desespero, porque tava super vazio...No inicio eu fiquei pensando em alguma alternativa, porque você viu que hoje várias crianças não quiseram ouvir a historinha... e tava meio vazio, né?" (Ana, Entrevista 4).

O feedback do trabalho do mediador do VIVA, por ele trabalhar geralmente sozinho, provem principalmente das crianças e de seus acompanhantes (nenhum mediador enfatizou a equipe profissional do hospital como fonte importante de feedback para sua atuação, embora alguns tenham mencionado que a aceitação do trabalho deles pela equipe médica tenha melhorado com o tempo). Potencialmente, isso pode ser um ponto de fragilidade para a motivação e a satisfação do mediador de leitura em seu cotidiano. Isso porque o feedback da criança e mesmo do acompanhante não dependem unicamente da atuação do mediador, mas também, de forma muito imediata, das condições físicas e psicológicas da criança e de quem as acompanha. Se isso é verdadeiro para qualquer situação de mediação de leitura, muito mais no caso de crianças hospitalizadas, que podem 
estar com dor, debilitadas, sob efeito de medicamentos e de possíveis intervenções médicas sofridas, etc. Assim, é importante que a organização possa oferecer condições para que as fontes de feedback do mediador não dependam apenas da criança e de seu acompanhante, mas que possam ser oferecidas de forma sistemática pela equipe que acompanha os voluntários, por meio de encontros periódicos de supervisão e troca de experiências, por exemplo, podendo incluir também cursos com especialistas em mediação de leitura.

\section{Dificuldades do mediador (15 proposições), Aprendizagem do Mediador (18 proposições) e Estratégias e recursos do mediador ( 25 proposições):}

As maiores dificuldades citadas pelos mediadores são as que se referem ao início da prática, logo após o curso inicial. "[Minha maior dificuldade] foi começar mesmo, perder a vergonha de não saber contar, de estar aprendendo a contar" (Beto, Entrevista 1). Logo em seguida, Beto descreve as dúvidas mais frequentemente enfrentadas na prática: O que é que eu leio? Como é que eu leio ? Como me apresento?...não tem jeito, acho que tem coisa que é só na prática que você aprende, só apanhando um pouquinho, que vai se adaptando." (Beto, Entrevista 1). Nota-se nessa última fala a proeminência da prática, que é citada pelos mediadores como forma principal de aprendizagem (12 proposições, e.g. "A prática diminui a dificuldade"; "A prática é a minha técnica" e "Tem coisa que você só aprende na prática"). Com menor frequência (4 proposições) é citada a aprendizagem por meio da observação de outros contadores mais experientes (talvez devido às parcas oportunidades de ver outros mediadores em ação):

"... quando eu vejo um outro contador, eu paro e vejo ele contando uma história, assim um contador com mais experiência, então eu paro e vejo como é que ele interagem, as vezes ele pega um personagem 'Ah, abre a mão pega nesse aqui...' ai assim, eu vou pegando uns macetes." (Beto, entrevista 1).

Quanto aos recursos e às estratégias usadas durante a interação com a criança, foram citados materiais como bonecos, dedoches, fantoches, música e roupas coloridas e também a linguagem corporal e voz para auxiliar na aproximação com a criança: "Eu uso o olhar", "O olhar ajuda na aproximação", "Eu utilizo vozes diferentes". As estratégias foram aprendidas na prática ou por meio da observação de outros mediadores. Notoriamente, a escolha da obra literária não foi citada entre as estratégias. As possíveis razões para essa ausência podem ter relação com as categorias discutidas a seguir.

\section{Leitura do contador (14 proposições):}

Esta categoria reuniu as proposições em que o mediador fala de suas próprias práticas de leitura, ponto fundamental quando levados em conta os objetivos do VIVA. Nessa categoria, houve 
menções ao gosto pela leitura ou pela literatura infantil de forma genérica (e.g., "Sempre gostei de ler"; "Gosto muito de literatura infantil"). A leitura feita pelo contador antecipadamente também é citada como um facilitador para a sua atuação, como uma preparação para a leitura compartilhada, (e.g., "Eu prefiro conhecer antecipadamente o livro" e "Eu leio o livro antes da contação":

"Isso foi até uma coisa que ensinaram no curso, a gente tem que estar sempre preparada, saber o que conta a história... se não pode colocar a gente em situações difíceis, né... (...) eu sempre treino fora daqui, contando a história pra alguém conhecido, antes de vir contar aqui (...) Eu não venho normalmente já sabendo o livro, mas eu sempre escolho um que eu já li, que já tenho familiaridade com a história, não é bom ser pega de surpresa...né?" (Ana, entrevista 1)

Nota-se que a leitura prévia aparece como um aspecto importante para o aperfeiçoamento da mediação, mas, sobretudo, como estratégia para evitar ficar em "situações difíceis" ou "ser pega de surpresa", no sentido de conhecer o conteúdo previamente e evitar situações de constrangimento. Exemplos dessas situações embaraçosas costumam ser dados nos cursos para alertar os mediadores sobre a importância de conhecer o que irão ler. A leitura prévia também é citada como modo de aprimoramento da leitura em voz alta e como forma de lidar melhor com a situação de mediação:

"....mas eu estudo mais em casa, chego em casa e pego os livros, compro livros, pra na hora ficar mais fácil, mas eu tenho sentido assim, que eu já estou melhorando, já tenho uma facilidade maior de lidar com as crianças, eu vou contando e aprimorando." (Beto, entrevista 1)

Cabe apontar que não houve menção a um outro objetivo possível da leitura prévia: conhecer e escolher boas obras para a mediação, com critérios baseados, por exemplo, no valor estético das palavras e das imagens. Esse ponto nos leva à próxima categoria analisada:

\section{Critérios para a escolha do livro (35 proposições):}

Quando os mediadores explicam como escolhem escolher os livros que irão ler com as crianças, são citados como critérios: (a) temas considerados importantes pelo mediador, e.g., "Eu acho importante ler livros de diversidade biológica" (Daniela, entrevista 1); (b) temas percebidos como sendo de preferência das crianças - nesse caso, às vezes as escolhas são feitas a partir de uma percepção de divisões entre gêneros: "Meninas gostam de livros de fadas, meninos de monstros" (Flávia, entrevista 2); (c) faixa etária: a idade é citada como critério, acompanhada da percepção de uma escassez ou de um desconhecimento de obras para crianças próximas da adolescência; (d) familiaridade: os mediadores dizem preferir histórias que já conhecem e leram outras vezes, que já mostraram ser de agrado das crianças.

Os três primeiros critérios citados têm em comum que deixam de fora a qualidade literária 
da obra, destacando escolhas por tema, gênero ou idade. Alguns estereótipos de gênero, muitas vezes reproduzidos pelas crianças (Filha, 2011) podem estar sendo reforçados na escolha dos mediadores. Também a divisão de obras literárias por faixa etária tem sido apontada como um equívoco, visto que centra a classificação em fronteiras arbitrárias de idade e desconsidera o potencial de aprendizagem (Vygotsky, 1978) e ignora a subjetividade, experiência e individualidade de cada criança, independente da sua idade (Azevedo, 2003). O uso desses critérios acaba se associando a dificuldades na hora de escolher a obra:

"A minha maior duvida, assim, é realmente... que eu ainda estou aprendendo ainda qual é o livro adequado para determinadas faixas etárias, que eu ainda estou aprendendo, uma faixa etária de uns quatro anos ainda não sei direito, porque não vai ser mais aquele livrinho só de figurinha, mas também não vai ser uma história tipo...é...uma história que ela não vai entender, então tem que ser uma história intermediaria que não seja tão bobinha, mas que também não seja mais aprofundada...então a dificuldade que ainda tenho é...mais essa: Saber qual é o material certo" (Beto, entrevista 1).

É claro que é impossível, na maioria dos casos, o mediador conhecer a criança e poder escolher a obra de acordo com aspectos individuais. Além disso, nas enfermarias, é comum ter que se ler para várias crianças que estão em fases de desenvolvimento diferentes, com diferentes histórias, gostos e personalidades (e também em condições diferentes de se engajar na atividade, relacionadas à medicação, dor, etc.). Mas essa é mais uma razão pela qual a idade não deve ser o principal critério de escolha, mantidas, é claro, certas questões de bom senso. Uma obra interessante para um leitor mais experiente pode não ser acessível para aquele que inicia seus contatos com os livros. No entanto, há inúmeras obras de qualidade que permitem a apreciação do texto e das imagens em vários níveis, que são interessantes e estimulantes para diversas idades e permitem leituras diversas a partir de diferentes fases do desenvolvimento. $\mathrm{O}$ fato, tantas vezes citado pelos próprios mediadores, de que uma boa história produz sempre a participação entusiasmada dos acompanhantes adultos, só confirma que a qualidade da obra, e não a faixa etária, deve prevalecer como critério na hora de escolher o que ler.

\section{Efeitos positivos da leitura/mediação para crianças (54 proposições):}

Esta categoria reuniu as proposições do mapa conceitual que expressaram benefícios da mediação de leitura (ou da leitura em geral) para as crianças. Uma boa parte das proposições desta categoria (20) expressam como principal ganho da mediação de leitura a distração da criança do contexto aversivo do hospital: distrair, trazer alegria, tirar do imediato, como exemplificado no seguinte trecho: 
"...falei: "vou começar a te contar uma historinha...' ele ficou fascinado! E olhando, começou a rir, dar gargalhada, ou seja eles mudam o astral na hora! Transformou-se completamente comparado com o que ele tava antes... É impressionante como eles têm uma reação com o livro..." (Ana, entrevista 2).

Posteriormente, a mesma mediadora relatou outro episódio:

"ele olhava sem parar pro livro, levantou a cabeça, já deu uma mudada no astral... e os pais impressionados, com a reação dele... porque o menino que tava ruim... não é que ele melhorou, né... mas pelo menos riu, deu gargalhada... bateu palma igual o personagem... e os pais ficaram emocionados..." (Ana, entrevista 2).

Menos citados, e de forma menos detalhada, foram os efeitos da leitura para a aprendizagem e o desenvolvimento infantil. Os mais citados foram ganhos genéricos ou que falam de forma ampla do "incentivo á leitura" (12 proposições), o "desenvolvimento da imaginação" (7 proposições) e a "melhora na aprendizagem escolar" (5 proposições). Outros benefícios, como ganho no vocabulário, formação de vínculos ou despertar da curiosidade, foram citados uma ou duas vezes mas de forma pontual, sem dar exemplos e em claro contraste com a ênfase e a vivacidade com que foram abordados os efeitos de distração do ambiente imediato que ela proporcionaria. Essa ênfase espelha uma concepção corrente do papel da leitura no hospital, destacado como "terapêutico" por Moreno et al., 2003), como um processo "catártico" (Ceribelli et al. 2009) ou como instrumento para a redução dos níveis de estresse (Caldin, 2002). Assim como nos estudos citados, o trabalho realizado pelos entrevistados deste estudo não é visto centralmente como um trabalho de formação de leitores, embora os exemplos que eles citam, de entusiasmo da criança, de envolvimento dos acompanhantes, de participação ativa das crianças, sugerem que ocorre ali um trabalho importante de aproximação das crianças e dos acompanhantes à narrativa literária, de uma forma lúdica e prazerosa. Como foi dito, o estudo de Flores et al. (2009) constatou que os mediadores interagem muito com as crianças durante a leitura e usam estratégias potencialmente benéficas para o desenvolvimento da compreensão leitora, da oralidade, da motivação para a leitura, dos vínculos afetivos, dentro outras (Campos, Luft, \& Wendling, 2013; Mesquita, 2014). No entanto, tais estratégias, realizadas na prática, não são explicitadas pelos mediadores em sua fala, que não parecem ter consciência de seu potencial. É possível que isso seja devido a uma confusão entre o a alfabetização estrita e o processo mais amplo de letramento e formação de leitores (Soares, 2003), ou seja, como os mediadores não fazem alfabetização no sentido estrito (e nem têm esse objetivo), acabam não concebendo seu trabalho como relevante para a formação de leitores. Também é possível que o local onde atuam desfavoreça a concepção de que estão formando leitores (o hospital 
não é percebido como um lugar onde ocorreria aprendizagem, que seria algo que só se daria na escola - ver Moura, Silva, Flores e Tunes, 2010). Finalmente, como foi visto, vários mediadores procuraram, em primeiro lugar, um trabalho voluntário, foram motivados pela vontade de contribuir socialmente, e só secundariamente se envolveram com a mediação de leitura. Seria importante, nesse sentido, que os momentos de formação enfatizassem esse aspecto central do trabalho realizado e seus potenciais impactos. Afinal, é por meio da experiência literária que se formam as bases, não só da alfabetização, mas de toda a experiência com o universo escrito e, para muitos autores, da construção e elaboração de perspectivas sobre o mundo e sobre si:

Em meio à avalanche de mensagens e estímulos externos, a experiência literária brinda o leitor com as coordenadas para que ele possa nomear-se e ler-se nesses mundos simbólicos que outros seres humanos construíram. E embora ler literatura não transforme o mundo, pode fazê-lo ao menos mais habitável, pois o fato de nos vermos em perspectiva e de olharmos para dentro contribui para que se abram novas portas para a sensibilidade e para o entendimento de nós mesmos e dos outros. (Reyes, 2011, p. 28).

\section{CONCLUSÃO}

Os principais temas abordados pelos entrevistados no presente estudo assemelham-se aos resultados apresentados em estudos anteriores com mediadores de leitura em hospital, incluindo o sentimento de gratificação e o feedback positivo das crianças (Caldin, 2002; Ceribelli et al., 2009), mas surgiram temas importantes que não haviam sido discutidos naqueles estudos, como a importância do direito de escolha da criança e o papel do acompanhante. Dificuldades e desafios na prática de mediação de leitura no hospital também foram mais detalhados pelos entrevistados deste estudo, em comparação, por exemplo, com Caldin (2002). Naquele estudo, vários mediadores relataram que substituíam a mediação de leitura pelo conto oral, mas atribuíram a dificuldade a fatores da criança, como sua pouca familiaridade com livros e com a situação de leitura. O presente estudo lança luz sobre possíveis relações entre as dificuldades na mediação de leitura e a concepção dos mediadores acerca do seu trabalho no hospital.

Os entrevistados deram muita ênfase à solidariedade associada ao papel do voluntário e à gratificação trazida pela certeza de se trazer um pouco de alegria e descontração para um ambiente visto como hostil. O fato de se trabalhar com livros parece ser visto quase como um acaso pelos mediadores, que, compreensivelmente, enfatizam muito mais o aspecto de alívio do sofrimento das crianças hospitalizadas. No entanto, a concepção de que o principal ganho da leitura seria a distração reflete uma concepção muito difundida da leitura, mas que é, segundo vários autores (e.g. 
Bértolo, 2014; Castrillón, 2011), equivocada, pois limita a leitura a uma função negativa ou escapista - ela faria bem pelo que retira (o ambiente aversivo do hospital, no caso em questão), e nada mais. Fica de fora dessa concepção o valor positivo do contato com a literatura, do que ela pode construir, e não apenas subtrair. A leitura compartilhada cria situações de intimidade com a linguagem oportunidades para a elaboração da situação vivida (Petit, 2009). A quase ausência dessa discussão possivelmente tenha relação com as dificuldades dos mediadores na escolha dos livros e o fato de eles não associarem a escolha de boas obras com o envolvimento das crianças. Seria importante oferecer espaços de estudo e reflexão sobre a centralidade da experiência literária no trabalho do mediador. Assim também, as demandas por feedback sobre seu trabalho e por apoio na escolha das obras sugerem a importância de se ampliarem as oportunidades de cursos com especialistas em mediação de leitura e de troca de experiências e observação mútua entre os mediadores.

\section{AGRADECIMENTOS}

Os autores agradecem a Anésio da Silva Batista, Camila Hernandez de Moura, Clara Coutinho, Daniel Yoneo Nakakura, Eloiza Mitsui Dias Sassaki, Erica Souza Mendes Machado, Esther S. Teixeira Bernardo, Lenice Maria O. de Carvalho, Maria do Socorro Ferreira Diniz, Mariana Guedes Coelho, Olide Salette C. Bigolin e Tanise Caroline Silva pelo auxílio na primeira fase de entrevistas e confecção dos mapas conceituais.

\section{REFERENCIAS}

ANDERSON, J. C., MOORE, L. F. The motivation to volunteer. Nonprofit and Voluntary Sector Quarterly, vol.7, n. 3.p. 120-129, 1978.

ARAÚJO, P. M., OLIVEIRA, F. Bem-estar no trabalho: impacto das percepções dos valores organizacionais e da confiança do empregado na organização. Horizonte Científico, vol. 1, n. 8, 2008. Disponível em: <http://www.seer.ufu.br/index.php/horizontecientifico/article/viewFile/3965/2953>

AZEVEDO, R. A didatização e a precária divisão de pessoas em faixas etárias: dois fatores no processo de (não) formação de leitores. In A. Paiva, A. Martins, G. Paulino \& Z. Versiani. (Eds.), Literatura e letramento: espaços, suportes e interfaces-o jogo do livro. Belo Horizonte: Autêntica. 2003. Disponível em http://www.ricardoazevedo.com.br/wp/wp-content/uploads/A-didatizacao-e-a-precaria-divisao-de-pessoas-em-faixasetarias.pdf.

BENSON, P. L. et al. Intrapersonal correlates of nonspontaneous helping behavior. The Journal of Social Psychology, vol. 110, n. 1, p. 87-95. 1998.

BÉRTOLO, C. O banquete dos notáveis: sobre leitura e crítica . Tradução: C. Tarrío. São Paulo: Livros da Matriz (Coleção Emília). 2014. 240p.

CASTRILlÓN, S. O direito de ler e de escrever. São Paulo: Pulo do Gato. 2011. 104p.

CAMPOS, S. D., LUFT, J. S., WENDLING, C. M. Iniciação à docência e formação de leitores. In: XI Seminário Nacional de Literatura, História e Memória e II Congresso Internacional de Pesquisa em Letras no contexto Latinoamericano, Caderno de resumos... Cascavel: Universidade Estadual do Oeste do Paraná, 2013, p. 28. 
CAVALCANTE, C. E., et al. No trabalho voluntário: estudo das relações entre comprometimento organizacional e desenho do trabalho. Estudos do CEPE, v.1, n.33, p. 206-230, 2011. Disponível em: https://online.unisc.br/seer/index.php/cepe/article/viewFile/1714/1408

CAVASSANI, A. P., BIAZIN, C.C. Qualidade de vida no trabalho: fatores que influenciam as organizações. Simpósio de Engenharia da produção, Anais... Simpósio, Bauru: Universidade Estadual Paulista, 2006. Disponível em: http://www.simpep.feb.unesp.br/anais/anais_13/artigos/694.pdf

CERIBELLI, C., et al. A mediação da leitura como recurso de comunicação com crianças hospitalizadas. Revista Latino-Americana de Enfermagem, v.17, n.1, p.81-87, 2009.

COYNE, I. Children's Experiences of Hospitalization. Journal of Child Health Care, v.10, n.4., p.326-336, 2006.

DAILEY, B. J. Using concept maps in qualitative research. In: A.J. Cañas, Novak, J.D., \& González, F. M. (Eds.), Concept Maps: Theory, Methodology, Technology. Proceedings of the First International Conference on Concept Mapping. Pamplona, Espanha: Universidad Pública de Navarra, 2004. Disponível em: http://cmc.ihmc.us/papers/cmc2004-060.pdf

DARLEY, J. M., BATSON, C. D.. From Jerusalem to Jericho: A study of situational and dispositional variables in helping behavior. Journal of Personality and Social Psychology, v.27, n.1, p. 100-108, 1973.

EISENBERG, N., MILLER, P. A. The relation of empathy to prosocial and related behaviors. Psychological Bulletin, v.101, n.1, p.91, 1987.

FILHA, C. X. Filha, C. X. (2011). Era uma vez uma princesa e um príncipe... Representações de gênero nas narrativas de crianças. Estudos Feministas, v.19, n.2, p.591-603, 2011.

FLORES, E. P., et al. Leitura compartilhada em um hospital pediátrico: análise do comportamento verbal dos contadores, Psicologia: Reflexão e Crítica, v. 26, n.4, p.711-720, 2013.

FUNCKE, A. L., PEREIRA, P. R. F., BOAS, A. A. V. Valores organizacionais relacionados ao trabalho voluntário: estudo de caso em ONG's do Rio de Janeiro. Caderno de artigos de Gestão de Pessoas, IV Simpósio de Excelência em Gestão e Tecnologia Resende: Associação Educacional Dom Bosco - AEDB, 2007. Disponível em:

http://ww.aedb.br/seget/artigos07/1251_Artigo\%20ONG.pdf.

INSTITUTO BRASILEIRO DE GEOGRAFIA E ESTATÍSTICA. Pesquisa de Assistência Médico-Sanitária, 2009. Disponívem em:

http://www.ibge.gov.br/home/estatistica/populacao/condicaodevida/ams/2009/ams2009.pdf. Acesso em 26 de Setembro, 2014,

KASHANI, J. H., BARBERO, G. J., BOLANDER, F. D. Depression in hospitalized pediatric patients. Journal of the American Academy of Child Psychiatry, v. 20, n.1, p. 123-134, 1982.

MESQUITA, F. A. Reflexões acerca do uso da de histórias para as crianças de 4 e 5 anos para o desenvolvimento da linguagem oral. Extensão em Ação, v.1, n.6, p. 87-95, 2014.

MORENO, R. L. R. et al. Contar histórias para crianças hospitalizadas: relato de uma estratégia de humanização. Pediatria, v.25, n. 4, p. 165-169, 2003.

MOURA, C. H., et al. A contação de histórias no ambiente hospitalar: uma forma de aprendizagem fora dos muros da escola. Anais... III Congresso Brasileiro Psicologia: Ciência e Profissão, 2010, São Paulo, SP, Brasil, 2010.

PEDROSO, D. O., et al. Importância da Motivação dentro das Organizações. Revista Ampla de Gestão Empresarial, Vol. 1, n. 5, p. 60-76, 2012.

PETIT, M. Petit, M. A arte de ler (ou como resistir à adversidade). Tradução Arthur Bueno e Camila Boldrini. 2a. ed. São Paulo: Editora 34, 2009.

SELLI, L, GARRAFA, V. Bioética, solidariedade crítica e voluntariado orgânico. Revista de Saúde Pública, v.39, n.3, p.473-478, 2005.

SELLI, L., GARRAFA, V., JUNGUES, J. R. Beneficiários do trabalho voluntário: uma leitura a partir da bioética.

Revista de Saúde Pública, v. 42, n.6, p. 1085-1089, 2008 a.

SIQUEIRA, S. R. Humanização e voluntariado: estudo qualitativo em hospitais públicos. Revista de Saúde Pública, v.44, n.5, p. 942-949, 2010.

SOARES, M. Alfabetização e letramento. São Paulo: Contexto, 2003. 